\title{
Correlation between Gastric Emptying Time and the Response of Pancreatic Polypeptide to Test Meals in Peptic Ulcer Diseases
}

\author{
Fumiaki Koizumi, Takeshi Kawamura, Akira Ishimori, \\ Hiroko Ebina* and Michinori Satoh* \\ Department of Clinical and Laboratory Medicine, Tohoku \\ University School of Medicine, Sendai 980 and \\ *Department of Gastrointestinal Medicine of Sendai \\ Hospital of Japanese National Railways, Sendai 980
}

Koizumi, F., Kawamura, T., Ishimori, A., Ebina, H. and Satoh, M. Correlation between Gastric Emptying Time and the Response of Pancreatic Polypeptide to Test Meals in Peptic Ulcer Diseases. Tohoku J. exp. Med., 1987, 151 (3), 275-281 — In the present study, pancreatic polypeptide (PP) levels both in basal state and after stimulation by meal were determined in 21 controls, 28 patients with gastric ulcer and 21 patients with duodenal ulcer and their correlation with gastric emptying was examined. In patients with gastric and duodenal ulcers, basal levels as well as stimulated of plasma PP during 95 min of observation period were higher than those in controls except for the values at $5 \mathrm{~min}$. As no correlation was seen between integrated $\mathrm{PP}$ response (IPPR) to the meal and $\mathrm{T}_{1 / 2}$ for gastric emptying in any of three groups, it was indicated that gastric emptying has only a minor role in postprandial PP response. pancreatic polypeptide; peptic ulcer; gastric ulcer; duodenal ulcer

Plasma concentration of pancreatic polypeptide $(\mathrm{PP})$ at basal state rises by cephalic-vagal stimulation induced by modified sham feeding (Taylor et al. 1978a ; Koizumi et al. 1984) and falls after injection of atropine and benzilonium (Schwartz et al. 1979). The fact that PP response to food is also inhibited by atropine (Taylor et al. 1978b), propantheline (Taylor et al. 1978a) and vagotomy (Schwartz et al. 1976; Taylor et al. 1978b) suggests that a cholinergic pathway is of major importance in basal as well as food-stimulated PP release. However, in some cases, little or no significant change is seen in basal PP concentrations after injection of atropine and benzilonium (Schwartz et al. 1978, 1979) or after truncal vagotomy (Schwartz et al. 1976; Taylor et al. 1978b). The plasma rise seen after meal in vagotomised patients was not significantly different from that in normal subjects (Adrian et al. 1977 ; Taylor et al. 1978a), indicating that non-cholinergic mechanism controlling $\mathrm{PP}$ release including gastric emptying time is partially

Received December 19, 1986 ; accepted for publication January 22, 1987. 
involved in basal levels as well as postprandial level.

Observations on PP levels in patients with peptic ulcer have been reported by some authors (Schwartz et al. 1976, 1978, 1979; Adrian et al. 1977; Stern and Hansky 1981 ; Gustavsson et al. 1982 ; Kunita et al. 1984 ; Sander-Jensen et al. 1985), although they are still contradictory. The purpose of the present study was to determine the fasting level and the meal-stimulated response of PP in peptic ulcer disease and to examine their correlation with gastric emptying time.

\section{Materials and Methods}

The study subjects included 21 controls, 28 patients with gastric ulcer and 21 patients with duodenal ulcer. The controls were free from any gastrointestinal disease or any systemic illness. Peptic ulcer was confirmed endoscopically and their ulcer stage is listed in Table 1. None of the patients had a history of previous gastric surgery. Informed consent was obtained from all subjects. A standard hospital lunch (25 g carbohydrate, $6.5 \mathrm{~g}$ fat and $10.2 \mathrm{~g}$ protein, $206 \mathrm{kcal}$ ) was prepared as outlined by Satoh et al. (1985), in which $1 \mathrm{mCi}$ dose of ${ }^{99 \mathrm{~m}} \mathrm{Tc}$-Sn colloid was mixed with the rice water. Immediately after ingestion of a meal, amount of isotope remaining in the stomach was determined at 15 min intervals for 65 min using a gamma camera (LFOV, Shimazu) and results were recorded on videotape. After the area of interest was obtained based on the recorded data, the gastric emptying rate was determined by Scinti-pac 230 (Shimazu) from the decreasing intragastric fraction of the total radioactivity determined at sequential scanning periods and the half-life of the meal in the stomach were calculated. Counts were taken in the standing position and subjects were permitted to move about freely between counts. The details of the method were described previously (Satoh et al. 1985).

Plasma levels of PP were determined by the previously described radioimmunoassay method (Koizumi et al. 1984) with slight modification using human PP (HPP) as the

TABLE 1. Clinical data

\begin{tabular}{|c|c|c|c|}
\hline Group & Sex & $\begin{array}{c}\text { Age } \\
\text { (year) }\end{array}$ & Stage $\ddagger$ \\
\hline $\begin{array}{l}\text { Controls } \\
\qquad(n=21)\end{array}$ & $\begin{array}{lr}\mathrm{M} & 21 \\
\mathrm{~F} & 0\end{array}$ & $33.9 \pm 2.4$ & - \\
\hline $\begin{array}{l}\text { Gastric ulcer } \\
\quad(n=28)\end{array}$ & $\begin{array}{lr}\mathrm{M} & 27 \\
\mathrm{~F} & 1\end{array}$ & $43.0 \pm 2.6 \dagger$ & $\begin{array}{cc}\mathrm{A} & 15 \\
\mathrm{H} & 11 \\
\mathrm{~S} & 2\end{array}$ \\
\hline $\begin{array}{l}\text { Duodenal ulcer* } \\
\quad(n=21)\end{array}$ & $\begin{array}{rr}\mathrm{M} & 21 \\
\mathrm{~F} & 0\end{array}$ & $37.7 \pm 2.3$ & $\begin{array}{l}\mathrm{A} \\
\mathrm{H} \\
\mathrm{S}\end{array}$ \\
\hline
\end{tabular}

* Two out of 21 patients with duodenal ulcer were complicated with pyloric stenosis.

$\dagger$ The mean age was significantly higher $(p<0.05)$ for the gastric ulcer patients than for the controls.

$\ddagger$ The time course of gastric ulcer was divided into three stages endoscopically according to the classificantion by Sakita et al. (Miyake et al. 1980). Sakita's classification was also used for staging of doudenal ulcer.

$\mathrm{A}$, active stage; $\mathrm{H}$, healing stage; $\mathrm{S}$, scarring stage. 


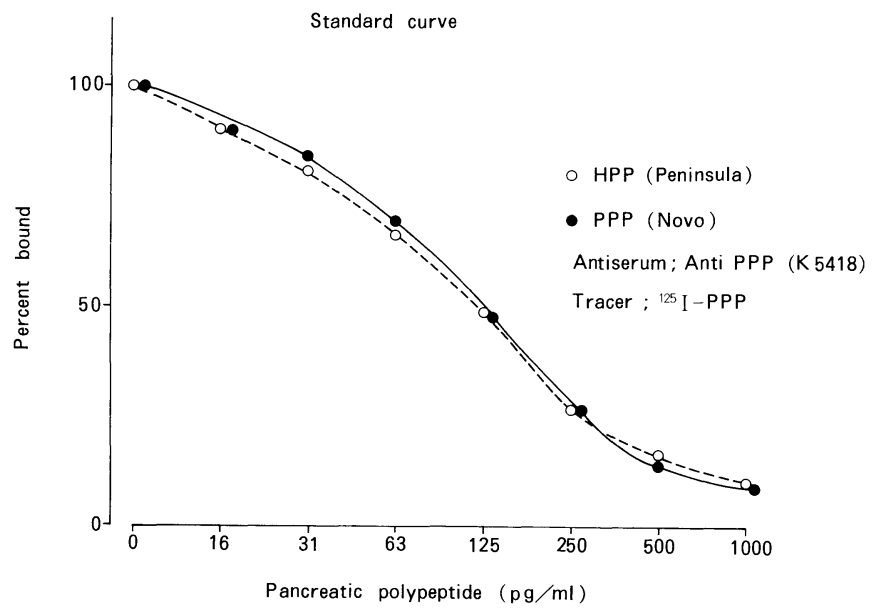

Fig. 1. Cross-reactivity of HPP and PPP with PPP antiserum. Standard curves of HPP and PPP were compared under identical assay conditions. Each point represents mean of 10 observations.

standard instead of porcine PP (PPP). The cross-reactivity of human PP was found to be identical to that of the porcine PP standard (Fig. 1). The coefficient of variation was 3.9\% for intraassay and $16.0 \%$ for interassay reproducibility.

\section{Statistics}

Data are presented as mean土s.E. For statistical analysis, Student's $t$-test for small paired and non-paired data was employed and $p$ values $<0.05$ were considered to be significant. Integrated PP response (IPPR) was calculated as the increase of PP above basal per unit time for the 95 min following a meal (Taylor et al. 1978a)

\section{Results}

\section{Gastric emptying}

Fig. 2 shows the composite emptying graph for the three groups. In controls, the mean isotope remaining in the stomach was $79.8 \pm 2.0 \%, 55.3 \pm 3.1 \%$, $36.0 \pm 2.9 \%, 25.2 \pm 2.0 \%$ and $20,35,50$ and 65 min, respectively. In patients with gastric and duodenal ulcers, the mean isotope retension was similar to that of controls with the exception of the value of $34.0 \pm 2.8 \%$ at $65 \mathrm{~min}$ in duodenal ulcer patient, which was significantly higher as compared to controls.

\section{Plasma PP}

In controls, the plasma PP rose from a basal level of $38.9 \pm 4.6 \mathrm{pg} / \mathrm{ml}$ to a peak of $88.8 \pm 8.7 \mathrm{pg} / \mathrm{ml}$ at $5 \mathrm{~min}(p<0.01)$. In gastric ulcer, the plasma PP rose from $55.9 \pm 4.1 \mathrm{pg} / \mathrm{ml}$ at basal state to a peak of $120.1 \pm 7.0 \mathrm{pg} / \mathrm{ml}$ at $20 \mathrm{~min}(p<$ 0.01). Similar PP levels were seen in age-matched group when compared to controls. In duodenal ulcer, the plasma PP rose from a basal level of $67.1 \pm 7.5$ $\mathrm{pg} / \mathrm{ml}$ to a peak of $130.2 \pm 10.6 \mathrm{pg} / \mathrm{ml}(p<0.01)$ at $20 \mathrm{~min}$ (Fig. 3). Although 


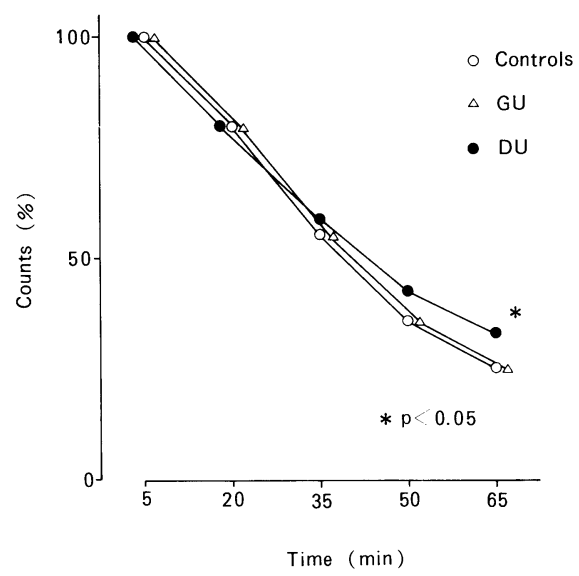

Fig. 2. Rate of gastric emptying in controls $(\bigcirc-\bigcirc)$, patients with gastric ulcer $(\triangle-\triangle)$ and patients with duodenal ulcer $(\bullet-\bullet)$. *indicates significant difference from controls.

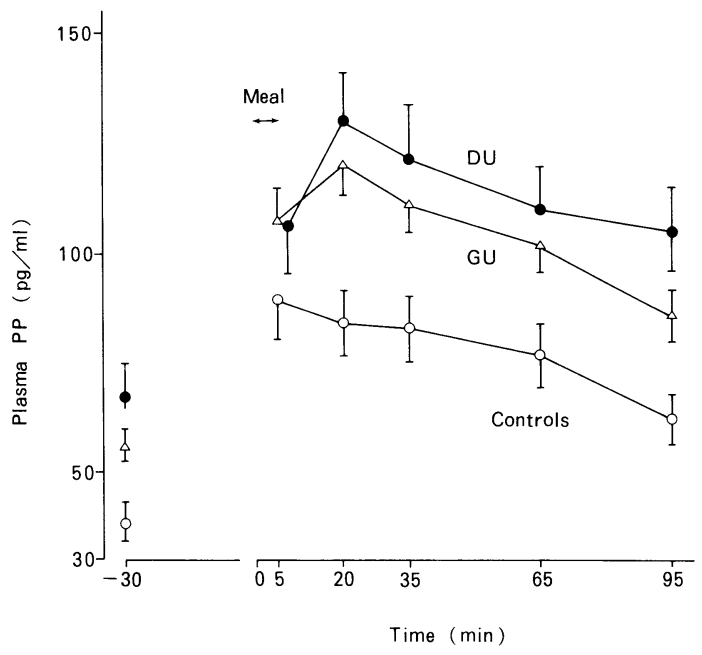

Fig. 3. Plasma PP concentrations following a test meal in controls $(\bigcirc-\bigcirc)$, patients with gastric ulcer $(\triangle-\triangle)$ and patients with duodenal ulcer $(\bullet-\bullet)$.

IPPR to food did not differ among three groups, plasma PP both of the basal and stimulated levels were significantly higher in patients with gastric and duodenal ulcers $(p<0.01)$ than the corresponding value in controls with the exception at 5 min after meal. No significant correlation between $\mathrm{T}_{1 / 2}$ for gastric emptying and IPPR was found as shown in Table 2. Nor any significant correlation was found between basal PP level, IPPR and age, although the coefficient of correlation $r$ was relatively higher in controls than in others (Table 3 ). 
TABLE 2. Correlation of $T_{1 / 2}$ for gastric emptying with IPPR

\begin{tabular}{lccrc}
\hline \multicolumn{1}{c}{ Group } & $\mathrm{T}_{1 / 2}$ & $\mathrm{IPPR}(\mathrm{ng} \cdot \mathrm{min} / \mathrm{ml})$ & $\mathrm{r}$ & $\mathrm{p}$ \\
\hline Controls & $39.2 \pm 2.1$ & $3.5 \pm 0.5$ & 0.0458 & $>0.5$ \\
Gastric ulcer & $40.3 \pm 1.8$ & $4.5 \pm 0.3$ & -0.0768 & $>0.5$ \\
Doudenal ulcer & $46.0 \pm 2.7$ & $4.5 \pm 0.4$ & 0.1475 & $>0.5$ \\
\hline
\end{tabular}

TABLE 3. Correlation of fasting PP level and IPPR with age

\begin{tabular}{lcc}
\hline \multicolumn{1}{c}{ Group } & Age vs. fasting PP & Age vs. IPPR \\
\hline Controls & $\mathrm{r}=0.1859, p>0.4$ & $\mathrm{r}=0.3255, p>0.1$ \\
Gastric ulcer & $\mathrm{r}=0.0521, p>0.5$ & $\mathrm{r}=0.0158, p>0.5$ \\
Duodenal ulcer & $\mathrm{r}=0.1556, p>0.4$ & $\mathrm{r}=-0.0524, p>0.5$ \\
\hline
\end{tabular}

\section{Discussion}

Most part of PP response after meal is mediated by vagal nerve. However, the exact mechanism by which food in the stomach releases PP via the nervous system remains unclear and it is possible that $\mathrm{PP}$ release into the blood may be influenced by gastric emptying as reported with other gastrointestinal hormone (Nakanome et al. 1983). But few studies about the correlation between PP response and gastric emptying time have been reported (Taylor et al. 1985).

It was previously shown that patients with duodenal ulcer had higher fasting and stimulated PP levels than controls (Schwartz et al. 1976, 1978; Gustavsson et al. 1982 ; Kunita et al. 1984). On the otherhand, others (Adrian et al. 1977 ; Stern and Hansky 1981 ; Sander-Jensen et al. 1985) have reported no differences between two groups. In contrast, in gastric ulcer patients, basal and stimulated PP levels were lower (Stern and Hansky 1981). It was shown from this study that both basal and food-stimulated PP levels during $95 \mathrm{~min}$ are significantly higher in gastric and duodenal ulcer patients than in controls except at 5 min, although IPPR for $95 \mathrm{~min}$ as a whole was not significantly different among three groups. As to the high level of PP in the postprandial state in peptic ulcers, no apparent correlation between IPPR and $T_{1 / 2}$ was seen and from these findings it was suggested that gastric emptying is not a major factor.

It has been reported that basal PP concentrations tend to increase with age (Berger et al. 1978; Schwartz et al. 1979). In our present study gastric and duodenal ulcer patients were relatively old, especially the latter patients were significantly older than controls. But differences in PP level between peptic ulcer patients and controls might not be attributable to differences in age since there was no correlation between age and basal PP levels.

PP may have a role in the regulation of biliary and pancreatic secretion (Adrian et al. 1978; Greenberg et al. 1979) which neutralize gastric acid delivered 
into the duodenum. However, it is uncertain whether high level of plasma PP in peptic ulcer patients may have a pathophysiological role in peptic ulcer disease.

\section{Acknowledgments}

We thank Miss Yumi Yamashita for her technical assistance.

\section{References}

1) Adrian, T.E., Bloom, S.R., Besterman, H.S., Barnes, A.J., Cooke, T.J.C., Russell, R.C. G. \& Faber, R.G. (1977) Mechanism of pancreatic polypeptide release in man. Lancet, 1, 161-163.

2) Adrian, T.E., Besterman, H.S., Mallinson, C.N., Greenberg, G.R. \& Bloom, S.R. (1978) Inhibition of secretin stimulated pancreatic secretion by pancreatic polypeptide. Gut, 20, 37-40.

3) Berger, D., Crowther, R.C., Floyd, J.C., Jr., Pek, S. \& Fajans, S.S. (1978) Effect of age on fasting plasma levels of pancreatic hormones in man. J. clin. Endocr., 47, 1183-1189.

4) Greenberg, G.R., McCloy, R.F., Chadwick, V.S., Adrian, T.E., Baron, J.H. \& Bloom, S.R. (1979) Effect of bovine pancreatic polypeptide on basal pancreatic and biliary outputs in man. Dig. Dis. Sci., 24, 11-14.

5) Gustavsson, S., Adami, H.O., Björklund, O., Enander, L.K., Lundqvist, G., Lööf, L. \& Nordahl, A. (1982) Fasting blood levels of gastrin, somatostatin, and pancreatic polypeptide in peptic ulcer disease. Scand. J. Gastroent., 17, 81-85.

6) Koizumi, F., Ushizawa, R., Kawamura, T., Ishimori, A. \& Sato, T. (1984) Plasma gastrin and pancreatic polypeptide response to atropine and sham feeding in man. Tohoku J. exp. Med., 142, 97-103.

7) Kunita, S., Kawanishi, M., Fujita, S., Sumii, K., Kajiyama, G., Yahata, N., Matsumoto, Y., Miyachi, Y. \& Miyoshi, A. (1984) PP and other hormone response to caerulein and secretin in the patients with duodenal ulcer. In: Proceedings of the Sixth Gut Hormone Conference, edited by Japanese Society of Gut Hormones, vol. 4, Igaku Tosho Shuppan, Tokyo, pp. 303-313. (Japanese)

8) Miyake, T., Suzaki, T. \& Oishi, M. (1980) Correlation of gastric ulcer healing features by endoscopy, stereoscopic microscopy, and histology, and a reclassification of the epithelial regenerative process. Dig. Dis. Sci., 25, 8-14.

9) Nakanome, C., Akai, H., Toyota, T. \& Goto, Y. (1983) Release of gastric inhibitory polypeptide in relation to gastric emptying in patients with duodenal ulcer. In : Gut Peptides and Ulcer, edited by A. Miyoshi, Biomedical Research Foundation, Tokyo, pp. $320-324$.

10) Sander-Jensen, K., Bonnevie, O. \& Schwartz, T.W. (1985) Vagal tone on the pancreatic polypeptide cell in duodenal ulcer patients. Correction for maximal and minimal secretory capacity. Scand. J. Gastroent., 20, 1097-1100.

11) Satoh, M., Ebina, H., Suzuki, S., Shidara, M. \& Tange, I. (1985) Gastric emptying cases of peptic ulcer and gastric cancer (part 1). J. Transport. Med., 39, 333-338. (in Japanese with English abstract)

12) Schwartz, T.W., Rehfeld, J.F., Stadil, F., Larson, L.I., Chance, R.E. \& Moon, N. (1976) Pancreatic-polypeptide response to food in duodenal-ulcer patients before and after vagotomy. Lancet, 1, 1102-1105.

13) Schwartz, T.W., Holst, J.J., Fahrenkrug, J., Jensen, S.L., Nielsen, O.V., Rehfeld, J.F., Schaffalitzky de Muckadell, O.B. \& Stadil, F. (1978) Vagal, cholinergic regulation of pancreatic polypeptide secretion. J. clin. Invest., 61, 781-789.

14) Schwartz, T.W., Stenquist, B., Olbe, L. \& Stadil, F. (1979) Synchronous oscillations in the basal secretion of pancreatic-polypeptide and gastric acid. Gastroenterology, 76, 
14-19.

15) Stern, A.I. \& Hansky, J. (1981) Pancreatic polypeptide release in gastric ulcer. Dig. Dis. Sci., 26, 289-291.

16) Taylor, I.L., Feldman, M., Richardson, C.T. \& Walsh, J.H. (1978a) Gastric and cephalic stimulation of human pancreatic polypeptide release. Gastroenterology, 75, $432-437$.

17) Taylor, I.L., Impicciatore, M., Carter, D.C. \& Walsh, J.H. (1978b) Effect of atropine and vagotomy on pancreatic polypeptide response to a meal in dogs. Amer. $J$. Physiol., 235, E443-E447.

18) Taylor, I.L., Gulsrud, P.O., Elashoff, J., Chew, P. \& Meyer, J.H. (1985) Gastric emptying and pancreatic polypeptide response to carbohydrate meals. Dig. Dis. Sci., 30, $52-57$. 